\title{
From the Editor-in-Chief
}

\section{Dear Readers,}

I accept the position of Editor-in-Chief of the Journal of the Society for Armenian Studies (JSAS) with great honor and sincere enthusiasm, and thank the Society for Armenian Studies for entrusting me with this task. This volume presents the first under my editorship, and our first volume published through the prestigious Brill, with whom we will be publishing both our online and print issues moving forward.

The launch of the JSAS with Brill marks a strategic and symbolic expansion. Propagating the goals of the journal's inaugural members, the journal will continue to facilitate scholarly exchanges, and through rigorous scholarship advance the field of Armenian Studies internationally.

As Editor-in-Chief, I am committed to upholding the journal to the highest of standards. I see editing as the extension of an ethical responsibility to service scholarly advancements in Armenian Studies, and to reconcile the field with developing global, transcultural, and interdisciplinary conversations. I see my role as a facilitator of voices, a mediator of information, and a promoter of texts and bodies that have not seen much scholarly attention in the past.

I serve my colleagues and readership as a translator; I see that ascription as also an obligation to keeping the field active and healthy. For this, I am dedicated to articles on subjects which broaden our understanding of the development of "Armenian Studies" as a field, that inform us of new discoveries, that break new theoretical ground, as well as those that extend beyond the temporal, geographic, and historical categories that traditionally defined Armenian Studies in the past.

As the first female Editor-in-Chief of the $J S A S$, I imagine my service as editor as one that also carries the legacy of foremothers, that considers the work of women as an integral part of its success and sustainability, and one that strives to consistently acknowledge how cultural and genealogical implications of gender formation intersect with research and scholarship.

I am thrilled to be working closely with a group of brilliant Review Editors, and with an Advisory and Editorial Board of pioneering colleagues. I am grateful for their input and dedication as generators of impactful direction, as they help me shape the journal for its long-term and international tenability. I also 
thank the authors who have contributed to this volume, as well as you, the readers, who have kept the journal alive for almost half a century.

Let us continue together as we keep the legacy of the JSAS alive. Collectively, we establish here, a distinguished venue, where we respectfully engage in scholarly dialogues that spark the discovery of new research avenues, that build and invite a community of interested scholars both in and outside the field, and that engage with cutting-edge research, as we continue to uphold the $J S A S$ to the standards set by its predecessors and us.

\section{Tamar M. Boyadjian}

Associate Professor of Medieval Literature, Department of English, Michigan State University, East Lansing, Michigan, USA;

Editor-in-Chief, Journal of the Society for Armenian Studies tamar@msu.edu 